\title{
0 impacto da desvinculação de receitas nos gastos com educação da União: uma análise entre os anos de 1994 a 2012
}

\author{
Janilson Antonio da Silva Suzart \\ Secretaria do Tesouro Nacional (STN) \\ Brasília / DF - Brasil
}

\begin{abstract}
A criação do Fundo Social de Emergência, em 1994, introduziu uma série de mecanismos utilizados pelo governo federal brasileiro para desvincular receitas de impostos e contribuições. Considerando essa situação, procurou-se identificar o possível impacto da desvinculação de receitas, em relação aos gastos com educação da União, realizados durante os anos de 1994 a 2012. Além da apuração do gasto realizado pelo governo federal com educação, foram computados os limites mínimos de gastos, considerando, em uma série, a redação original da Constituição Federal de 1988 e, na outra, a redação modificada pela inserção/alteração dos mecanismos de desvinculação. De acordo com as análises realizadas, não há indícios de que a desvinculação tenha afetado os gastos com educação, que foram superiores aos limites, em média e nos anos analisados.
\end{abstract}

Palavras-chave: educação; desvinculação; DRU; direitos sociais; gastos com educação.

El impacto de la desvinculación de los ingresos en el gasto en educación de la Unión: un análisis entre los años 1994-2012

La creación del Fondo de Emergencia Social, en 1994, introdujo una serie de mecanismos utilizados por el gobierno federal de Brasil para desvincular los ingresos tributarios y contribuciones. Teniendo en cuenta esta situación, el presente trabajo buscó identificar el posible impacto de la desvinculación de los ingresos a respecto de los gastos en la educación de la Unión, llevada a cabo durante los años 1994 a 2012. Además de la determinación de los gastos del gobierno federal destinados a la educación, se calcularon los límites mínimos de gasto, mientras que, en una serie, siguió el texto original de la Constitución de 1988 y, la otra, el texto modificado por la inserción/modificación de los mecanismos de desvinculación. Según el análisis, no hay pruebas de que la desvinculación ha afectado el gasto en educación, que fueron superiores a los límites medios en los años analizados.

Palabras clave: educación; desvinculación; DRU, derechos sociales, gasto en educación.

DOI: http://dx.doi.org/10.1590/0034-7612132753

(cc) BY-NC

Artigo recebido em 31 mar. 2014 e aceito em 26 jan. 2015.

${ }^{1} \mathrm{O}$ presente artigo representa a opinião do seu autor e não a opinião institucional da entidade.

Rev. Adm. Pública - Rio de Janeiro 49(4):869-887, jul./ago. 2015 
The impact of decoupling revenue in education spending of the Union: an analysis between the years 1994-2012

The creation of the Emergency Social Fund, in 1994, introduced a number of mechanisms used by the Brazilian federal government to decouple tax revenues and contributions. Considering this situation, this paper tried to identify the possible impact of decoupling revenue over expenditure on education of the Union, conducted during the years1994-2012. Besides the verification of the expenses undertaken by the federal government on education, they were computed the minimum spending limits, considering in a series, the original text of the Constitution of 1988 and in another series, the text modified by the insertion/ modification of decoupling mechanisms. According to the analysis, there is no evidence that decoupling has affected education spending, which were higher than the limits, on average and in the years analyzed.

Keywords: education; decoupling; DRU; social rights; education spending.

\section{Introdução}

A Constituição Federal de 1988 foi responsável pela transição para um regime democrático, implementação de reformas político-administrativas e consolidação de direitos sociais. Essas e outras atribuições vinculadas à criação de um Estado capaz de respeitar a dignidade humana fizeram com que a constituição brasileira fosse considerada a "Constituição Cidadã" (Guimarães, 1988).

Dentre os direitos sociais expressos na Constituição Federal encontra-se a educação. A educação é um "direito de todos e dever do Estado e da família" (Brasil, 1988), e, por isso, o acesso aos diferentes níveis formais de educação precisa estar inserido e implementado pelas políticas públicas formuladas pelos governos nacional e subnacionais brasileiros.

O acesso à educação, assim como ocorre com outros direitos sociais, gera a criação de obrigações positivas para os entes públicos (Barcellos, 2008). Dessa forma, tais entes precisam desenvolver atividades visando a oferta de serviços educacionais à sociedade, implicando a realização de gastos.

De maneira similar a alguns direitos sociais, os legisladores constituintes criaram vinculações orçamentárias, com o objetivo de garantir fontes de recursos para financiar os gastos necessários ao acesso à educação. As vinculações orçamentárias são mecanismos que reservam uma parcela ou o total de certas receitas públicas para finalidades específicas, direcionando a atuação estatal.

Todavia, além da garantia à educação, os legisladores constituintes criaram um número elevado de vinculações orçamentárias, o que implicou a redução da flexibilidade orçamentária dos gestores públicos. Além da rigidez orçamentária, a presença das vinculações ganha especial importância diante da limitação de recursos para fazer face aos gastos impostos pela Carta Magna brasileira.

Para melhor compreensão desse cenário, o Ministério do Planejamento, Orçamento e Gestão (2003) descreve que, em 1988, cerca de 55,5\% das receitas da União estavam desvinculadas e que, já em 2002, esse percentual era tão somente 19,4\%. Nota-se que as vinculações orçamentárias afetaram o poder de escolha dos gestores públicos, em relação à definição das áreas atendidas pelos gastos governamentais. 
Visando solucionar o problema da rigidez orçamentária, foi criado o Fundo Social de Emergência (Brasil, 1994), cuja justificativa para sua criação foi o fato de o fundo ser uma "medida necessária à estabilidade econômica" (Dias, 2011). De forma efetiva, o fundo compreendia um mecanismo para desvincular uma parcela das receitas da União ao estabelecer, em linhas gerais e com algumas restrições, a liberação de $20 \%$ das receitas oriundas de tributos e contribuições de competência da União.

Por um lado, a desvinculação de receitas da União propiciou a devolução de parte da flexibilidade orçamentária que possuíam os gestores públicos. Por outro lado, ela reduziu a base de cálculo utilizada na apuração de algumas vinculações orçamentárias, estabelecidas pelo legislador constituinte, para o atendimento de direitos sociais, dentre eles a educação.

A redução dos recursos vinculados não representa necessariamente uma redução dos gastos relativos à garantia dos direitos sociais. A flexibilidade orçamentária não implica não utilização dos recursos para o atendimento de direitos sociais, a não ser que as escolhas dos gestores divirjam das áreas prioritárias estabelecidas constitucionalmente.

A partir do contexto anteriormente apresentado surge a questão norteadora da presente pesquisa: qual o impacto da desvinculação das receitas da União em relação aos gastos relacionados com educação no período entre 1994 e 2012 ?

Considerando o questionamento anterior, a presente pesquisa possui como objetivo principal identificar o possível impacto da desvinculação em relação aos gastos com educação da União, durante o período de 1994 a 2012. De maneira suplementar, a pesquisa objetiva:

a. Analisar a evolução da desvinculação das receitas da União, desde a sua primeira versão do ano de 1994;

b. Descrever a inserção do direito à educação e seu financiamento nas constituições brasileiras, desde a época do Império aos dias atuais; e

c. Discutir o financiamento da educação de acordo com a Constituição Federal de 1988.

O presente artigo está composto das seguintes partes: (1) introdução, parte que está sendo apresentada; (2) plataforma teórica, onde estão apresentadas as discussões sobre a relação entre a desvinculação de receitas da União e o financiamento do acesso à educação; (3) metodologia, parte na qual são descritos os principais procedimentos realizados durante a pesquisa; (4) análise dos resultados, onde são relatadas as principais evidências da pesquisa; e (5) considerações finais, parte destinada à apresentação das conclusões e limitações da pesquisa.

\section{Plataforma teórica}

\subsection{A desvinculação de receitas da União}

A desvinculação de receitas da União (DRU) compreende um conjunto de dispositivos que foram implementados por sucessivas emendas constitucionais, cujo objetivo é ampliar a flexibilidade orçamentária, ao anular o efeito das vinculações estabelecidas pelos legisladores 
constituintes, em especial, em relação aos impostos e contribuições. A principal finalidade da DRU é ampliar o volume de recursos livres para que os gestores públicos possam direcionar os gastos públicos.

Antes da Constituição Federal de 1988, os gestores públicos podiam alocar discricionariamente uma parcela razoável das receitas públicas. Por exemplo, no ano de 1988, cerca de 55,5\% das receitas arrecadadas pela União estavam desvinculadas (Ministério do Planejamento, Orçamento e Gestão, 2003). Todavia, a atual Constituição institui vinculações orçamentárias que fazem com que uma parcela das receitas somente possa ser utilizada para determinados gastos.

Dias (2011) descreve que, antes da implantação do Plano Real em 1994, a União conseguia apresentar resultados positivos em razão das altas taxas de inflação. Entretanto, para continuar a apresentar resultados positivos após a implantação do plano (cuja meta prioritária foi o controle da taxa inflacionária), foi proposta a criação do Fundo Social de Emergência (FSE), visando a estabilização da economia, por meio da Emenda Constitucional de Revisão no 1 (Brasil, 1994).

Os dispositivos que criaram a desvinculação foram se sucedendo até a data de hoje. Após a vigência do FSE, entre 1994 e 1995, vieram o Fundo de Estabilização Fiscal (FEF), vigente entre 1996 e 1999, e a DRU, vigente a partir de 2000 até os atuais dias. No quadro 1 são apresentados os conjuntos de dispositivos utilizados para fomentar a desvinculação de receitas do governo federal.

Quadro 1

Dispositivos que tratam da DRU

\begin{tabular}{|lll|}
\hline Denominação & Norma & Vigência \\
\hline Fundo Social de Estabilização & Emenda Constitucional de Revisão no 1/1994 & 1994 e 1995 \\
Fundo de Estabilização Fiscal & Emenda Constitucional no 10/1996 & 1996 e 1997 (1o sem.) \\
& Emenda Constitucional no 17/1997 & 1997 (2o sem.) a 1999 \\
Desvinculação de Receitas da União & Emenda Constitucional no 27/2000 & 2000 a 2003 \\
& Emenda Constitucional no 42/2003 & 2003 a 2007 \\
& Emenda Constitucional no 56/2007 & 2008 a 2011 \\
\hline
\end{tabular}

Fonte: Dados da pesquisa (2013).

O FSE tinha como finalidade o "saneamento" das finanças públicas e a estabilização econômica do país (Brasil, 1994). O governo federal buscava criar um ambiente econômico estável para garantir que o Plano Real fosse implementado e consolidado. Todavia, tal situação somente seria possível se o próprio governo estabilizasse suas próprias finanças, bem como as dos governos subnacionais brasileiros. De acordo com a norma criadora do FSE (Brasil, 1994), os seguintes recursos seriam transferidos para o respectivo fundo: 
a. O imposto sobre a renda retido na fonte sobre quaisquer pagamentos efetuados pelo governo federal;

b. O acréscimo da arrecadação dos impostos sobre a propriedade territorial rural, sobre a renda e proventos de qualquer natureza e sobre as operações financeiras, conforme alterações na legislação tributária vigente à época;

c. O acréscimo oriundo do aumento da alíquota da contribuição social sobre o lucro das instituições financeiras;

d. $20 \%$ das receitas de todos os impostos e contribuições da União, desconsiderados os itens anteriores;

e. A contribuição para o Programa de Integração Social devida pelas instituições financeiras; e

f. Outras receitas especificadas na legislação.

Dias e Tavares (1999) descrevem que não houve mudança significativa entre o FSE e o FEF. Apenas, ressaltam que a Emenda Constitucional no 17 (Brasil, 1997) obrigou a União a repassar para os municípios um percentual da arrecadação do imposto de renda considerado na constituição do Fundo de Participação dos Municípios (FPM), em taxas crescentes de 1,56\%, 1,875\% e 2,5\%, respectivamente, para os anos de 1997 (segundo semestre), 1998 e 1999. Tal dispositivo, segundo Dias e Tavares (1999), funcionou como uma espécie de ressarcimento da União para aqueles governos subnacionais, em razão da redução da base de cálculo do FPM ocorrida anteriormente.

Na prática, os FSE e FEF nunca corresponderam ao conceito de fundo de acordo com a legislação brasileira (Dias e Tavares, 1999; Scaff, 2004). Esses fundos serviram para atenuar o déficit das finanças públicas e devolver uma parte da discricionariedade dos gestores públicos, em matéria de alocação de gastos (Dias e Tavares, 1999; Pinto, 2008).

Após a vigência do FEF, a Emenda Constitucional ํo 27 (Brasil, 2000b) não criou outro fundo, mas consolidou a ideia de desvinculação, dando origem à denominada DRU. Para os anos de 2000 a 2003, ficaram desvinculadas $20 \%$ das receitas oriundas dos impostos e das contribuições sociais, sendo, todavia, respeitadas as bases de cálculos utilizadas para as transferências aos governos subnacionais e as "aplicações em programas de financiamento ao setor produtivo das regiões Norte, Nordeste e Centro-Oeste" (Brasil, 2000b). Também foi excluída a contribuição social do salário-educação (Brasil, 2000b).

A partir do ano de 2004, a Emenda Constitucional no 42 (Brasil, 2003) também incluiu no rol das receitas desvinculadas as relativas às contribuições de intervenção no domínio econômico (Cide). A Emenda Constitucional no 59 (Brasil, 2009) anulou o efeito da desvinculação para "cálculo dos recursos para manutenção e desenvolvimento do ensino", parcialmente nos anos de 2009 e 2010 e totalmente no ano de 2011. Tal situação foi mantida pela Emenda Constitucional no 68 (Brasil, 2011).

Outras parcelas que têm sido excluídas do cálculo são as relativas às contribuições sociais do regime geral de previdência social e do regime próprio de previdência dos servidores 
públicos federais. Segundo Dias (2011), tais exclusões têm sido feitas por intermédio de dispositivos contidos nas leis de diretrizes orçamentárias.

De maneira resumida, de acordo com a redação da Carta Magna (Brasil, 2011), em relação aos dispositivos da desvinculação, a DRU pode ser calculada da seguinte forma:

Quadro 2

\section{Cálculo da DRU}

\begin{tabular}{|ll|}
\hline Receitas & Parcela da DRU \\
\hline Receitas de impostos & (A) 20\% das receitas de impostos \\
\hline Receitas de contribuições sociais & \\
(-) Multas, juros e recebimentos da dívida ativa & \\
(-) Contribuições para a previdência social & (B) 20\% das receitas líquidas de contribuições \\
(-) Contribuições para o salário-educação & sociais \\
$\begin{array}{ll}\text { (-) Parcela da CPMF (contribuição provisória sobre movimentação financeira) } \\
\text { para o Fundo de Combate e Erradicação da Pobrezaa }\end{array}$ \\
$\begin{array}{ll}\text { (-) Contribuição para o regime próprio de previdência social (RPPS) } \\
=\text { Receitas líquidas de contribuiç̃̃es sociais }\end{array}$ \\
\hline Receitas de contribuições de intervenção no domínio econômico & (C) 20\% das receitas de contribuições de \\
\hline Total das receitas desvinculadas & intervenção no domínio econômico \\
\hline
\end{tabular}

Fonte: Dados da pesquisa (2013).

Nota:

a. Atualmente, apenas saldos residuais. A CPMF vigorou até o ano de 2007.

b. Atualmente, apenas saldos residuais. As alíquotas da Cide foram zeradas para os itens relativos a combustíveis pelo Decreto $\mathrm{n}$ ․ 7.764, de 22 de junho de 2012.

Por fim, destaca-se que a DRU tem como principal papel auxiliar no atingimento da meta de superávit fiscal (Dias, 2011). A flexibilidade orçamentária propiciada pela DRU faz com que os gestores públicos federais consigam utilizar os recursos, visando a formação do superávit fiscal. Apesar de o superávit fiscal ser utilizado, principalmente, para o pagamento de juros e do principal da dívida pública, isso necessariamente não significa que os recursos desvinculados são utilizados exclusivamente para o pagamento da dívida.

No próximo item, passa-se à discussão da educação como direito social.

\subsection{A educação como direito social}

Na Constituição Federal brasileira foram consagrados como direitos sociais: (1) educação; (2) saúde; (3) alimentação; (4) trabalho; (5) moradia; (6) lazer; (7) segurança; (8) previdência social; (9) proteção à maturidade e à infância; e (10) assistência aos desamparados. Aos go- 
vernos nacional e subnacionais cabem "proporcionar os meios de acesso à cultura, à educação e à ciência" (Brasil, 1988).

Ainda segundo a Constituição brasileira, a educação é um "direito de todos e dever do Estado e da família", servindo para o desenvolvimento das pessoas, do ponto vista profissional e de cidadania (Brasil, 1988).

Ranieri (2009) destaca que a educação é um direito social diferenciado em relação aos demais, por ser compulsório, ao menos nos primeiros níveis de ensino. Além de ser uma obrigação do Estado, a educação é, também, dever da família, o que torna impositivo o exercício desse direito.

Em relação ao dever da família, Maliska (2001) descreve que os pais, além de terem obrigação de assegurar a educação aos seus filhos (dever constitucional de educar), possuem o direito prioritário de escolha do gênero de educação que a seus filhos será ofertado.

O acesso à educação, no caso brasileiro, deverá ser ofertado observando-se os seguintes princípios: (1) igualdade de condições de acesso e permanência; (2) liberdade de pensamento; (3) pluralismo de ideias; (4) coexistência de instituições públicas e privadas de ensino; (5) gratuidade e universalidade do ensino; (6) valorização dos profissionais; (7) gestão democrática no ensino público; e (8) piso salarial nacional (Brasil, 1988).

De acordo com Teixeira (2008), a educação sempre figurou como direito nas Constituições brasileiras. Na época do Brasil Império (1822-89) havia "a garantia do ensino primário a todos os cidadãos e sua realização, preferencialmente, pela família e pela Igreja”. A primeira Constituição do período republicano ampliou de forma limitada a participação do Estado na garantia do acesso à educação, apenas assegurando a separação entre a Igreja e o Estado, também, no campo educacional (Teixeira, 2008).

Rocha (2000) descreve que somente na Constituição Federal de 1934 houve ampliação da participação do Estado na garantia à educação. Além da reafirmação do direito à educação, Rocha (2001) destaca a "aplicação de recursos públicos" e "a participação da União em todos os níveis de ensino", dentre outras, como as principais questões abordadas na respectiva Constituição. Teixeira (2008) complementa, afirmando que naquela Constituição a educação fundamental foi caracterizada como direito subjetivo público, ou seja, é um direito assegurado a todos, mesmo para aquelas pessoas que não usufruíram dela na idade adequada.

Na Constituição Federal de 1946 foram estabelecidas as primeiras vinculações de recursos para a educação. Segundo Oliveira (2001), a União deveria gastar pelo menos 10\% da receita dos impostos arrecadados, enquanto os governos subnacionais, $20 \%$. Tais vinculações foram suprimidas na Constituição Federal de 1967 (Teixeira, 2008).

Teixeira (2008) destaca que, durante o período da ditadura militar (1964-85), as principais mudanças constitucionais relacionadas ao direito à educação foram: (1) "substituição da liberdade de cátedra pela liberdade de comunicação de conhecimentos no exercício do magistério" e (2) "obrigatoriedade para investimentos foi estabelecida somente aos municípios", sendo em 1983 estendida tal obrigatoriedade para os demais entes federados.

Observa-se que o direito à educação sofreu algumas modificações, ao longo dos períodos imperial e republicano brasileiros, sendo a Carta Magna de 1988 aquela em que esse 
direito foi amplamente tratado. Além da inclusão da educação no rol dos direitos sociais, a Constituição Federal vigente (Brasil, 1988) fixou: (1) os princípios norteadores para o ensino; (2) a autonomia universitária; (3) as obrigações estatais em relação à oferta de serviços educacionais; (4) a participação de entidades privadas na oferta de serviços educacionais; (5) a competência dos entes federados; (6) as fontes de financiamento da educação; (7) a possibilidade de transferência de recursos públicos para as escolas comunitárias, confessionais ou filantrópicas; e (8) o estabelecimento do plano e do sistema nacional de educação.

Ainda sobre a Constituição Federal vigente, destaca-se que o ensino fundamental e a educação infantil são de responsabilidade prioritária dos municípios, enquanto que estados e Distrito Federal têm como prioritários o ensino fundamental e o médio (Brasil, 1988). Atualmente, a União dedica-se ao ensino técnico-profissionalizante e ao ensino superior.

Dentre os temas tratados na Carta Magna de 1988, destaca-se o financiamento da educação, que é discutido no item seguinte.

\subsection{0 financiamento da educação na Constituição Federal de 1988}

Para garantir direitos de seus cidadãos, o Estado pode se omitir (obrigação negativa) ou agir (obrigação positiva) (Barcelos, 2008). Quando o Estado não interfere nas atividades dos cidadãos, ocorre a omissão estatal que pode garantir, por exemplo, o direito à liberdade de expressão ou à liberdade de trânsito. Quando o Estado oferta bens e/ou serviços, direta ou indiretamente, aos cidadãos, ocorre a ação estatal que pode garantir, por exemplo, o direito à educação e à saúde.

Garantir o acesso à educação, bem como aos demais direitos sociais, exige a ação estatal, que implicará a realização de gastos por parte do Estado. Conforme destacam Holmes e Sunstein (2000), qualquer garantia de direitos pelas entidades públicas conduzirá à realização de gastos, que se converterão em bens e/ou serviços à população.

$\mathrm{Na}$ Constituição Federal brasileira foram estabelecidas vinculações orçamentárias como meio de garantir o financiamento dos gastos necessários à efetivação de alguns dos direitos sociais, como foi o caso da educação. Os legisladores constituintes buscaram direcionar a atuação dos gestores públicos, estabelecendo o atendimento de finalidades específicas. Dessa forma, os legisladores estabeleceram limites mínimos de gastos a serem observados pelos entes federados, em relação a alguns dos direitos sociais.

Nesse sentindo, Scaff (2004) complementa que, além das vinculações, a partilha de receitas entre os entes federados e a criação de novas fontes de recursos (como foi a criação da contribuição provisória sobre a movimentação financeira - CPMF) foram outros meios utilizados pelos legisladores para direcionar os gestores públicos para a implementação de direitos sociais.

Em relação à educação, a União deve aplicar pelo menos $18 \%$ e os estados, o Distrito Federal e os municípios, $25 \%$ "da receita resultante de impostos, compreendida a proveniente de transferências na manutenção e desenvolvimento do ensino" (Brasil, 1988). Além dessa 
vinculação, a "educação básica pública terá como fonte adicional de financiamento a contribuição social do salário-educação" (Brasil, 1988). Destaca-se, em relação aos limites mínimos de gastos, que a União e os estados devem deduzir das receitas de impostos a parcela sujeita às transferências obrigatórias.

A criação de fundos é um dos principais mecanismos para se operacionalizar as vinculações orçamentárias. Os fundos, ou fundos especiais, conforme denominados na legislação, representam o montante de receitas vinculadas à realização de objetivos ou serviços específicos (Brasil, 1964). Os recursos que são transferidos para um fundo, salvo disposição legal em sentido contrário, permanecerão no respectivo fundo até sua utilização, mesmo que esse uso somente ocorra em exercício posterior ao do recebimento do recurso.

Na atualidade, os principais fundos utilizados pela União para garantir o acesso à educação são: (1) o Fundo de Manutenção e Desenvolvimento da Educação Básica e da Valorização dos Profissionais da Educação (Fundeb); (2) o Fundo Nacional de Desenvolvimento da Educação (FNDE); e (3) o Fundo de Financiamento ao Estudante do Ensino Superior (Fies).

A Emenda Constitucional no 14 (Brasil, 1996) criou o Fundo de Manutenção e Desenvolvimento do Ensino Fundamental e de Valorização do Magistério (Fundef). Sendo implementado a partir de 1998, o Fundef compreendia um fundo especial cujos recursos recebidos eram repassados para os governos subnacionais, responsáveis pela realização dos gastos. Além disso, a norma criadora do Fundef estabeleceu nova sistemática dos limites mínimos constitucionais para estados, Distrito Federal e municípios, ou seja, 60\% dos recursos oriundos dos limites constitucionais para os gastos com a manutenção e o desenvolvimento do ensino deveriam ser destinados para o ensino fundamental (na prática, $25 \% \times 60 \%=15 \%$ das receitas de impostos, incluindo as transferências obrigatórias recebidas e excluindo as transferências obrigatórias realizadas) (Brasil, 1996).

O Fundef foi substituído pelo Fundeb, por meio da Emenda Constitucional no 53 (Brasil, 2006). O Fundeb preservava a característica de fundo cujos recursos eram redistribuídos para os governos subnacionais, porém sendo destinado ao fomento do ensino básico. Para sua operacionalização foram criados fundos específicos para cada unidade federativa. As principais características do Fundeb, que o diferencia do anterior, são as seguintes: (1) vigência de 14 anos (a do Fundef era de 10 anos); (2) a educação básica abrange a educação infantil, o ensino fundamental e o ensino médio; e (3) o aumento de $15 \%$ para $20 \%$, gradativamente em três anos, dos recursos alocados no fundo, oriundos de transferências obrigatórias recebidas pelos governos subnacionais.

O FNDE foi criado pela Lei no 5.537 (Brasil, 1968) e representa ao mesmo tempo um fundo especial e uma autarquia federal. Como autarquia, o FNDE é vinculado ao Ministério da Educação (MEC) e tem como objetivo executar ações de apoio à educação básica e prestar auxílio financeiro e técnico aos governos subnacionais. O FNDE é também responsável pelo apoio e financiamento de projetos de ensino e pesquisa, incluindo, além da educação básica, o ensino superior e o ensino técnico.

Os principais recursos transferidos para o FNDE são: (1) dotações consignadas nos orçamentos anuais da União; (2) recursos provenientes de incentivos fiscais; (3) parcela das 
receitas das loterias federais; (4) recursos provenientes da contribuição social do salário-educação; (5) doações; e (6) receitas patrimoniais.

O Fies foi criado pela Lei no 10.260 (Brasil, 2001) e é o fundo "destinado à concessão de financiamento a estudantes regularmente matriculados em cursos superiores não gratuitos e com avaliação positiva nos processos conduzidos pelo Ministério da Educação". Existe ainda a possibilidade de recursos do Fies serem destinados ao financiamento de cursos da educação profissional e tecnológica. Os principais recursos transferidos para o Fies compreendem: (1) dotações orçamentárias consignadas ao MEC; (2) parcela das receitas das loterias federais; e (3) taxas, emolumentos, encargos e sanções relacionados com o processo de seleção e as operações de financiamento.

\section{Metodologia}

A presente pesquisa busca analisar o comportamento dos gastos realizados pelo governo federal brasileiro com a educação e a possível influência da desvinculação de receitas nesses gastos, durante o período compreendido entre 1994 e 2012, ou seja, desde a vigência do primeiro mecanismo de desvinculação de receitas, o FSE. Também foram simulados os limites mínimos de gastos federais com a educação, considerando a redação original da Constituição Federal de 1988 e as redações modificadas em razão da inclusão/alteração do FSE (1994 e 1995), do FEF (1996 a 1999) e da DRU (2000 a 2012).

Em primeiro lugar, foram obtidos e organizados os dados sobre as receitas e os gastos do governo federal brasileiro para o período em análise. A obtenção desses dados foi realizada a partir de consultas ao sítio da Secretaria do Tesouro Nacional (<www.tesouro.fazenda.gov. br $>$ ). Os dados foram obtidos a partir das demonstrações contábeis e das acessórias divulgadas pela respectiva Secretaria.

Em segundo lugar, foram calculados os limites mínimos com gastos com educação. Considerando os dados relacionados com as receitas de impostos arrecadados pela União, foram calculados os limites mínimos, formando-se duas séries: (1) a primeira desconsiderou as presenças do FSE, do FEF e da DRU (denominada de limite mínimo sem DRU, doravante), ou seja, foi considerada a redação original da Constituição Federal de 1988; e (2) a segunda considerou as presenças dos mecanismos de desvinculação de receitas (denominada limite mínimo com DRU, doravante), correspondendo ao limite obrigatório vigente no período em análise. A base de cálculo compreendeu a diferença entre o total das receitas de impostos e as transferências obrigatórias da União para os governos subnacionais.

Os gastos relacionados com a educação (gasto realizado, doravante) foram obtidos considerando-se a classificação funcional dos gastos públicos. Até o ano de 1999, de acordo com o Anexo V da Lei no 4.320 (Brasil, 1964), os gastos com educação eram classificados na função "6 - Educação e Cultura". A partir do ano de 2000, de acordo com a Portaria no 42 (Ministério do Orçamento e Gestão, 1999), foram criadas as funções "12 - Educação" e "13 - Cultura", compreendendo os gastos realizados com educação e cultura, respectivamente. 
Considerando que os gastos com cultura representaram, em média, menos que 3\% dos gastos com educação durante o período de 2000 a 2012, a influência dos gastos com cultura foi considerada insignificante para fins de análise. Desse modo, a série dos gastos com educação do governo federal brasileiro foi formada da seguinte maneira: (i) de 1994 a 1999, compreende os gastos realizados na função "6 - Educação e Cultura"; e (ii) de 2000 a 2012, compreende os gastos realizados na função "12 - Educação".

Para comparar os comportamentos das séries gasto realizado, limite mínimo sem DRU e limite mínimo com DRU foi escolhida a técnica da análise gráfica. Além de serem apresentados os comportamentos para o período total em análise, foram realizados cortes temporais nas séries, de forma a analisar as tendências e as possíveis anormalidades identificadas.

Além da análise gráfica, procurou-se identificar para todo o período analisado se as três séries, anteriormente citadas, possuíam diferenças estatisticamente significativas em relação às suas médias. Para isso, foi realizado, inicialmente, o teste de detecção de normalidade Shapiro-Wilk. No caso de todas as séries possuírem distribuição normal, seria utilizada a análise de variância (Anova). No caso negativo, seria utilizado o teste Kruskal-Wallis. Em todos os testes estatísticos realizados foi considerado o nível de significância de 5\%.

\section{Análises dos resultados}

Inicialmente, as séries gasto realizado, limite mínimo com DRU e limite mínimo sem DRU são exibidas no gráfico 1, compreendendo o período entre 1994 e 2012.

\section{Gráfico 1}

Gastos com educação - União - 1994 a 2012

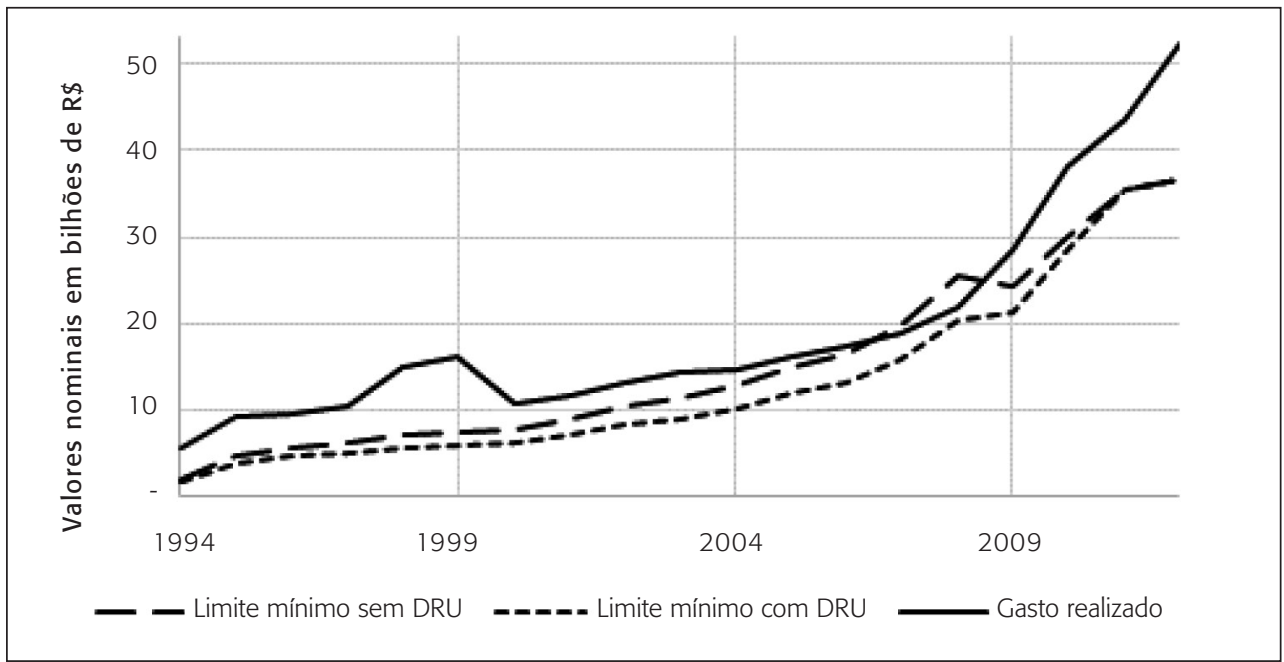

Fonte: Dados da pesquisa (2013). 
Observa-se no gráfico que a relação entre o gasto realizado e os limites mínimos não foi constante durante todo o período analisado. O gasto realizado nunca foi inferior ao limite mínimo computado considerando-se os efeitos da DRU, o que seria natural, pois a situação em contrário implicaria sanções aos gestores, por descumprimento de cláusulas constitucionais. Nos anos de 2007 e 2008, verifica-se que o gasto realizado foi inferior ao limite mínimo sem DRU, fato relevante que será analisado mais adiante.

Em relação ao comportamento das séries, quatro subperíodos apresentam mudanças de tendência. São eles: (i) de 1994 a 1999; (ii) de 2000 a 2006; (iii) de 2007 a 2008; e (iv) de 2009 a 2012. Na sequência, é analisado cada um dos subperíodos destacados.

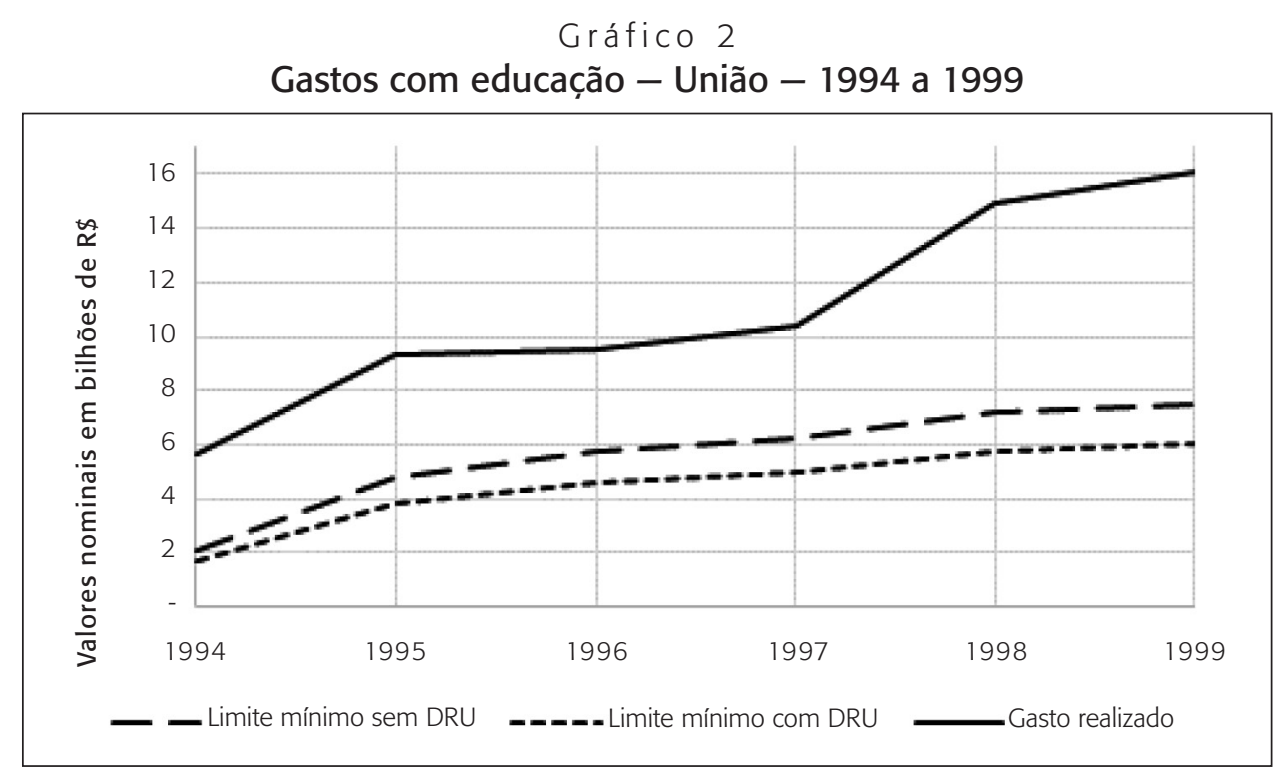

Fonte: Dados da pesquisa (2013).

O período entre 1994 e 1999 abrange a vigência dos dois primeiros mecanismos de desvinculação de receitas da União (o FSE e o FEF). Também nesse período os gastos com cultura eram agrupados aos gastos com educação, de acordo com a classificação funcional adotada à época.

Visualmente, percebe-se que o gasto realizado pelo governo federal foi bem superior a ambos os limites. Ressalta-se que, mesmo que fosse possível descontar os gastos com cultura, não haveria modificação significativa dessa relação, pois os gastos com cultura representaram menos que 3\% dos gastos com educação, considerando o efeito calculado para o período entre 2000 e 2012, quando esses gastos começaram a ser demonstrados separadamente.

Nesse período, o gasto realizado, em média, compreendeu cerca de duas vezes o limite mínimo, desconsiderando o efeito das desvinculações, e duas vezes e meia o limite mínimo constitucional vigente à época. Nota-se que a ocorrência das desvinculações de receitas não afetou os gastos com educação nos períodos em que estiverem vigentes o FSE e o FEF. 


\section{Gráfico 3}

Gastos com educação - União - 1999 a 2006

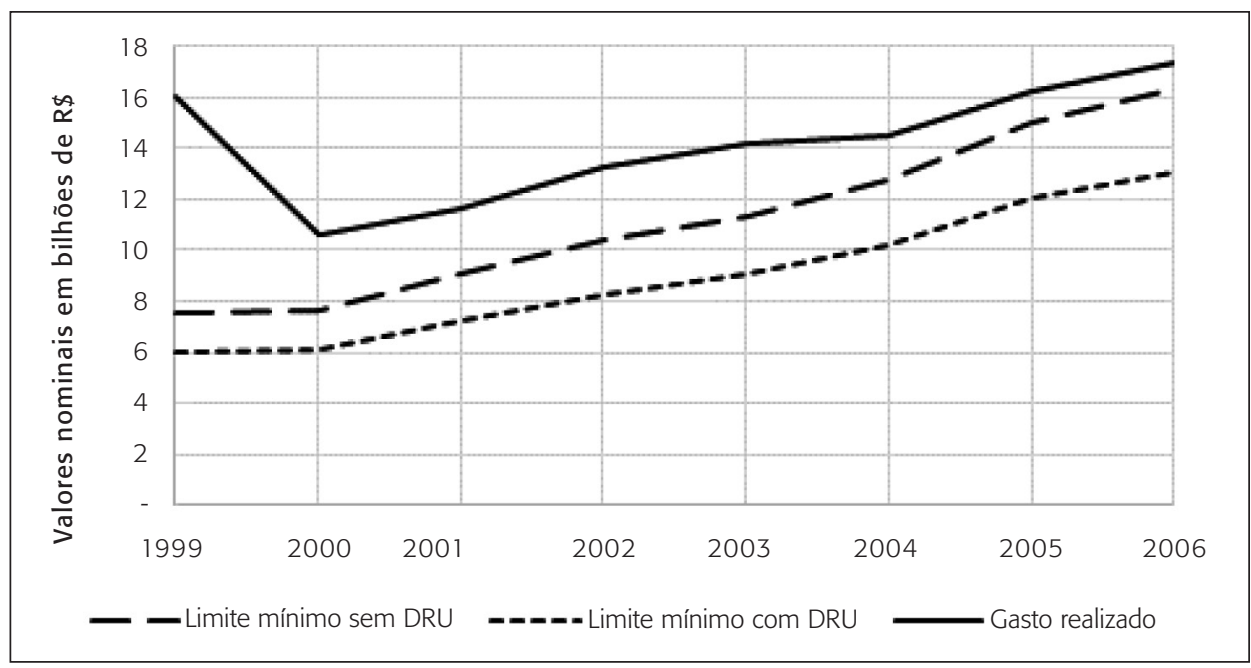

Fonte: Dados da pesquisa (2013).

No período de 2000 a 2006, percebe-se a primeira mudança na relação entre as séries analisadas. Durante o período anterior, o gasto realizado foi bem superior aos limites mínimos, porém, nesse, o gasto realizado esteve levemente acima de ambos os limites.

Nesse período estava vigente a DRU, último e atual mecanismo utilizado para a desvinculação de receitas, e houve a mudança de classificação funcional dos gastos públicos, com a segregação dos gastos com educação e dos com cultura. Todavia, a mudança da relação não parece decorrer dessa situação, pois, conforme foi dito anteriormente, os gastos com cultura corresponderam a menos que 3\% dos gastos com educação realizados entre 2000 e 2012 .

A mudança da relação entre as séries decorre, provavelmente, das seguintes situações: (1) crescimento das receitas de impostos a partir desse período; e (2) mudanças nas escolhas orçamentárias, decorrentes das políticas públicas feitas pelos gestores do período, marcado por transição e ascensão de outro grupo político ao governo federal.

Nos anos de 2007 e 2008 ocorreu nova mudança na relação das séries analisadas. Nesses anos, o gasto realizado foi inferior ao limite mínimo, considerando a redação original da Carta Magna de 1988. Entretanto, o gasto realizado continuou acima do limite mínimo obrigatório.

No ano de 2007, os gastos com educação equivaleram a 95,9\% do limite mínimo sem DRU, que foi de 19,9\%, aproximadamente, superior ao limite mínimo obrigatório. No ano de 2008, a distância foi maior, e o gasto realizado correspondeu a $86 \%$ do limite mínimo, desconsiderando a desvinculação. Todavia, em 2008, o gasto realizado foi 7,6\% superior ao limite mínimo constitucional vigente, isso é, considerando-se os efeitos da DRU à época. 
Gráfico 4

Gastos com educação - União - 2006 a 2009

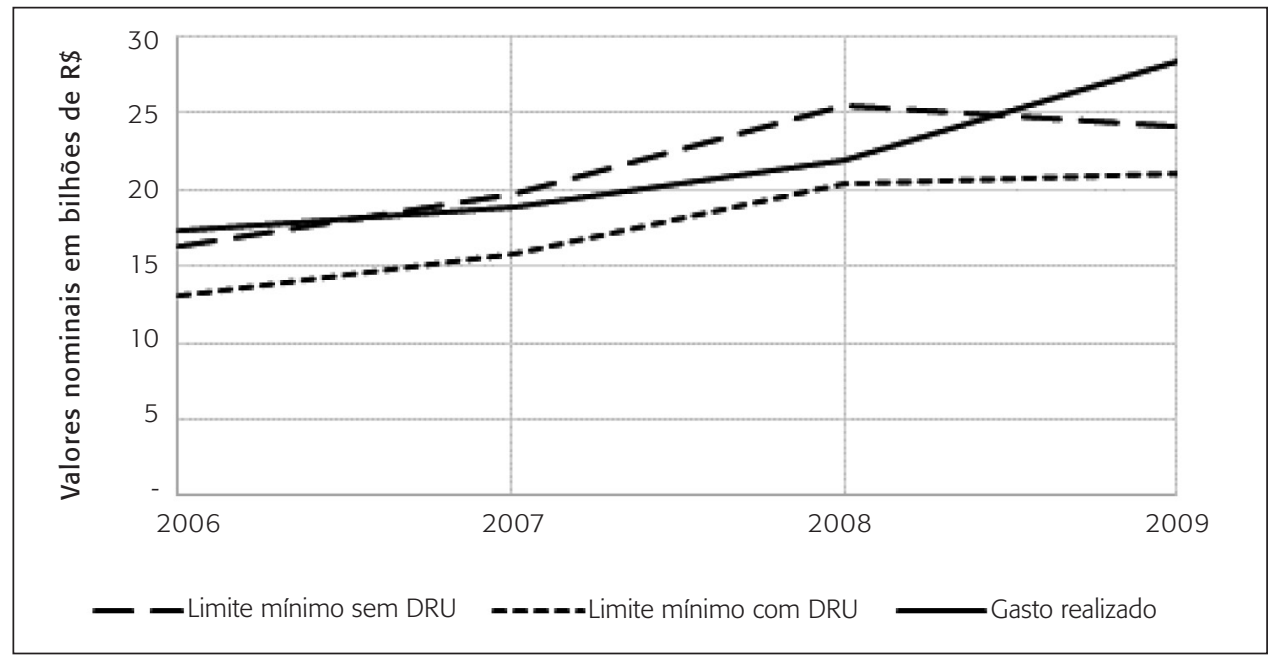

Fonte: Dados da pesquisa (2013).

A princípio, nesse período, parece que a DRU influenciou na redução dos gastos com educação. Entretanto, para analisar a real influência da DRU, faz-se necessário avaliar as condições orçamentárias do período.

Nos anos em análise, o governo federal contingenciou, respectivamente, cerca de seis e 11 bilhões de reais. O contingenciamento compreende o bloqueio de crédito, de modo que os gastos realizados sejam inferiores às despesas orçamentárias autorizadas, criando-se uma economia de recursos que ajudará na formação do superávit. Em uma análise realizada pelo Tribunal de Contas da União (2012), verificou-se que durante os anos de 2007 e 2011 "o contingenciamento da despesa realizada pelo governo federal nos últimos anos" interferiu, até mesmo, "na execução das ações prioritárias".

Observa-se que o contingenciamento se converte no principal responsável pela redução de gastos com educação e de outros gastos governamentais, nos anos de 2007 e 2008 , e não a DRU. Todavia, em especial no ano de 2008, fica evidente que o governo federal fez uso do limite mínimo constitucional de gastos com educação, considerando o efeito da DRU na redução desse valor.

O último período em análise compreende os anos de 2009 a 2012. Nesse período, a Emenda Constitucional no 59 (Brasil, 2009) anulou parcialmente o efeito da DRU em relação ao limite mínimo dos gastos com educação, nos anos de 2009 e 2010, e totalmente, a partir de 2011. Isso pode ser observado, pois as séries dos limites se colapsam a partir daquele ano.

Esse período foi marcado por nova mudança no comportamento das séries. O gasto realizado voltou a ser superior a ambos os limites mínimos. Considerando o limite mínimo sem DRU, o gasto realizado foi, em média, superior a 27,6\%, aproximadamente. Em relação ao limite mínimo vigente, o gasto realizado foi cerca de 33,6\% superior, em média. 


\section{Gráfico 5}

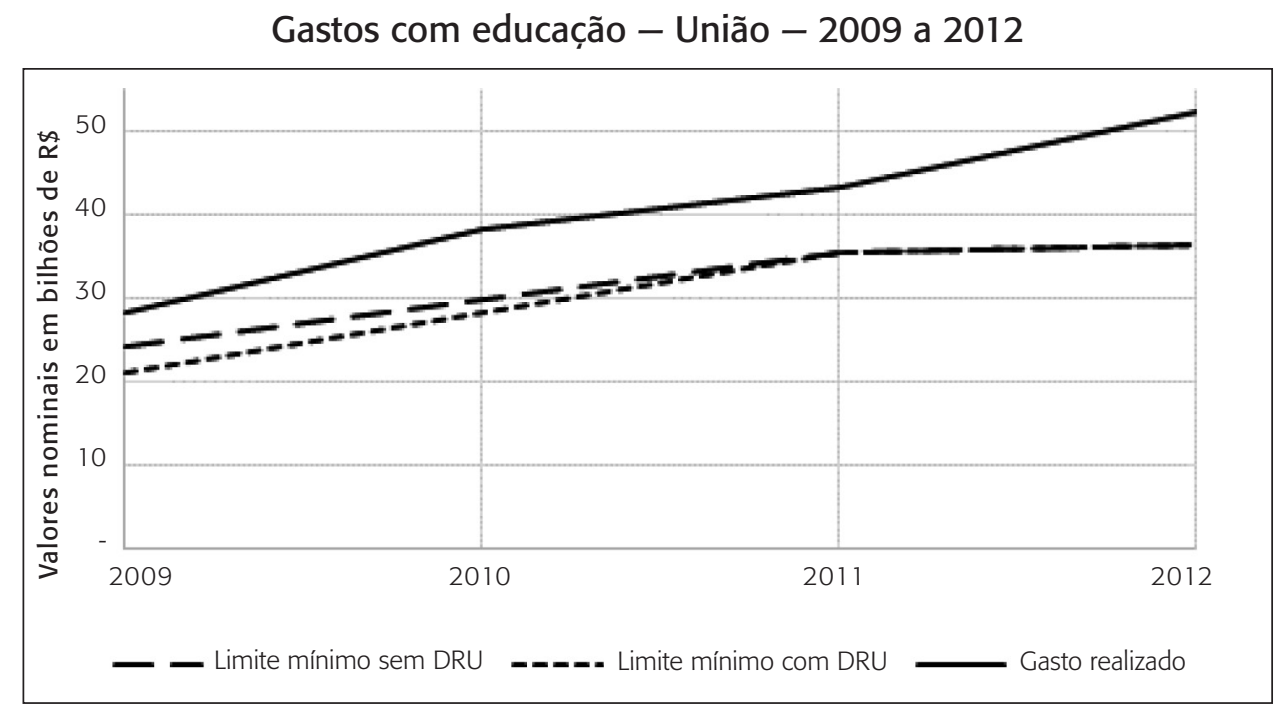

Fonte: Dados da pesquisa (2013).

Observa-se que, durante esse período, o governo federal voltou a gastar mais recursos com a educação, demonstrando que a DRU não interferiu no processo de alocação desses gastos. Destaca-se, ainda, que a anulação dos efeitos da DRU no limite de gastos mínimos com educação e as melhorias no cenário econômico ajudaram na retomada do comportamento de crescimento acima do limite.

Na próxima tabela são apresentados os resultados dos testes Shapiro-Wilk para a detecção de normalidade das séries, bem como algumas estatísticas descritivas.

Tabela 1

Resultados dos testes Shapiro-Wilk e estatísticas descritivas

\begin{tabular}{|lccccc|}
\hline \multirow{2}{*}{ Séries } & \multicolumn{3}{c}{ Estatísticas descritivas ${ }^{\text {a }}$} & \multicolumn{2}{c|}{ Teste Shapiro-Wilk } \\
\cline { 2 - 6 } & Média & Mediana & Desvio-padrão & Estatística & Probabilidade \\
\hline Gasto realizado & 19,316 & 14,901 & 12,571 & 0,804 & 0,001 \\
Limite mínimo sem DRU & 15,123 & 11,336 & 10,559 & 0,842 & 0,005 \\
Limite mínimo com DRU & 13,189 & 9,069 & 10.553 & 0,889 & 0,031 \\
\hline
\end{tabular}

Fonte: Dados da pesquisa, 2013.

Nota: (a) Valores nominais em bilhões de reais.

Durante o período em análise, o gasto realizado, o limite mínimo sem DRU e o limite mínimo com DRU alcançaram valores médios, em bases nominais, de 19,3, 15,1 e 13,2 bilhões de reais, respectivamente. 
De acordo com o teste Shapiro-Wilk, as estatísticas de todas as séries resultaram em probabilidades inferiores a 5\%, implicando a rejeição da hipótese nula de que as séries possuam distribuição normal. Em razão de tais resultados, foi realizado o teste Kruskal-Wallis, conforme descrito na metodologia, sendo os resultados apresentados na tabela seguinte.

Tabela 2

Resultados do teste Kruskal-Wallis

\begin{tabular}{|llll|}
\hline \multirow{2}{*}{ Séries } & \multicolumn{2}{c|}{ Teste Kruskal-Wallis } \\
\cline { 2 - 4 } & Ranking médio ${ }^{\text {a }}$ & Estatística & Probabilidade \\
\hline Gasto realizado & 35,37 & & 0,090 \\
Limite mínimo sem DRU & 27,95 & 4,823 & \\
Limite mínimo com DRU & 23,68 & & \\
\hline
\end{tabular}

Fonte: Dados da pesquisa, 2013.

Nota: (a) Valores nominais em bilhões de reais.

Com uma probabilidade superior a 9\%, o teste Kruskal-Wallis indicou que as médias das séries analisadas são estatisticamente iguais, considerando-se um nível de significância de 5\%. Entretanto, o ranking médio indicou que, apesar de não haver diferenças significativas entre as séries, a série gasto realizado está em posição superior às demais séries. Como era de se esperar, a série limite mínimo sem DRU está em posição superior à série limite mínimo com DRU, indicando que a DRU apenas afetou o cálculo do limite de gastos, apesar de tal afetação não ser significativa.

Dessa maneira, observa-se que a DRU não afetou, do ponto de vista estatístico, a média dos gastos com educação, realizados pelo governo federal, em relação às médias dos limites mínimos, no período entre 1994 e 2012. Observa-se que as afetações pontuais nos anos de 2007 e 2008 não foram significativas no período.

\section{Considerações finais}

Os mecanismos de desvinculação de receitas estão presentes na Constituição Federal brasileira desde o ano de 1994. Tais mecanismos permitem que uma parcela de recursos, anteriormente vinculada, possa ser utilizada discricionariamente pelos gestores. O aumento da flexibilização orçamentária propiciada pela DRU pode conduzir à impressão de que houve (ou haverá) redução nos gastos sociais, tendo em vista a afetação das fontes vinculadas.

Até o ano de 2010, os mecanismos de vinculação afetaram o cálculo do limite mínimo de gastos com a educação, ao liberarem, principalmente, $20 \%$ da parcela das receitas de impostos. Partindo dessa constatação, buscou-se identificar o possível impacto da desvinculação de receitas da União, em relação aos gastos com educação, realizados no período entre 1994 e 2012. 
Na análise gráfica realizada, foram identificados quatros momentos distintos na relação entre o gasto realizado e os limites mínimos, computados com e sem os efeitos da DRU: (i) de 1994 a 1999, no qual o gasto realizado correspondia a pelo menos duas vezes os limites mínimos; (ii) de 2000 a 2006, onde o gasto realizado foi apenas um pouco superior aos limites; (iii) de 2007 a 2008, período em que o gasto realizado foi superior apenas ao limite mínimo obrigatório (considerando a DRU); e (iv) de 2009 a 2012, onde o gasto realizado voltou a ser superior aos limites.

Notou-se que, nos anos de 2007 e 2008, o gasto realizado foi inferior ao limite mínimo, computado a partir da redação original da Constituição Federal de 1988. Entretanto, tal situação estava diretamente relacionada com o contingenciamento realizado pelo governo federal, especialmente em função da crise econômica internacional. A política de contingenciamento praticada nos últimos anos pelo governo federal, apesar de ser uma medida necessária ao ajuste fiscal, afeta áreas prioritárias ao bem-estar da sociedade brasileira, dentre elas a garantia aos direitos sociais.

Com exceção dos anos de 2007 e 2008, os gastos com educação sempre foram, numérica e nominalmente, superiores aos limites mínimos com e sem a DRU. Tais evidências conduzem à afirmação de que no período em análise não há indícios de que os mecanismos da DRU tenham afetado os gastos com a garantia daquele direito social.

Tal assertiva é corroborada a partir dos resultados dos testes estatísticos realizados. Apesar de não haver diferenças significativas entre o gasto realizado e os limites mínimos, a média do primeiro foi considerada superior às médias das demais séries.

Destaca-se que os resultados da presente pesquisa ficam limitados à estratégia metodológica escolhida. Outras estratégias podem conduzir a novas evidências favoráveis ou contrárias às aqui apresentadas, convertendo-se a escolha de novas estratégicas em sugestão para futuras pesquisas. Outra sugestão refere-se a uma análise mais minuciosa das condições orçamentárias e financeiras do governo federal nos anos de 2007 e 2008.

\section{Referências}

BARCELLOS, Ana P. Constitucionalização das políticas públicas em matéria de direitos fundamentais: o controle político-social e o controle jurídico no espaço democrático. In: SARLET, Ingo W.; TIMM, Luciano B. (Org.). Direitos fundamentais: orçamento e "reserva do possível". Porto Alegre: Livraria do Advogado Editora, 2008. p. 111-147.

BRASIL. Constituição da República Federativa do Brasil de 1988. 1988. Disponível em: <www.planalto.gov.br/ccivil_03/constituicao/constituicao.htm>. Acesso em: 8 abr. 2013.

BRASIL. Emenda Constitucional de no 14, de 12 de setembro de 1996. 1996. Disponível em: <www. planalto.gov.br/ccivil_03/constituicao/Emendas/Emc/emc14.htm>. Acesso em: 2 maio 2013.

BRASIL. Emenda Constitucional de no 17, de 22 de novembro de 1997. 1997. Disponível em: <www. planalto.gov.br/ccivil_03/constituicao/Emendas/Emc/emc17.htm>. Acesso em: 11 abr. 2013. 
BRASIL. Emenda Constitucional de no 26, de 14 de fevereiro de 2000. 2000a. Disponível em: <www. planalto.gov.br/ccivil_03/constituicao/Emendas/Emc/emc26.htm>. Acesso em: 19 abr. 2013.

BRASIL. Emenda Constitucional de no 27, de 21 de março de 2000. 2000b. Disponível em: <www. planalto.gov.br/ccivil_03/constituicao/Emendas/Emc/emc27.htm>. Acesso em: 11 abr. 2013.

BRASIL. Emenda Constitucional de no 42, de 19 de dezembro de 2003. 2003. Disponível em: <www. planalto.gov.br/ccivil_03/constituicao/Emendas/Emc/emc42.htm>. Acesso em: 11 abr. 2013.

BRASIL. Emenda Constitucional de noำ53, de 19 de dezembro de 2006. 2006. Disponível em: <www. planalto.gov.br/ccivil_03/constituicao/Emendas/Emc/emc53.htm>. Acesso em: 11 abr. 2013.

BRASIL. Emenda Constitucional de no 59, de 11 de novembro de 2009. 2009. Disponível em: <www. planalto.gov.br/ccivil_03/constituicao/Emendas/Emc/emc 59.htm>. Acesso em: 11 abr. 2013.

BRASIL. Emenda Constitucional de nº 68, de 21 de dezembro de 2011. 2011. Disponível em: <www. planalto.gov.br/ccivil_03/constituicao/Emendas/Emc/emc68.htm>. Acesso em: 11 abr. 2013.

BRASIL. Emenda Constitucional de Revisão no1, de 01 de março de 1994. 1994. Disponível em: <www. planalto.gov.br/ccivil_03/constituicao/emendas/ECR/ecr1.htm>. Acesso em: 10 abr. 2013.

BRASIL. Lei no 4.320, de 17 de março de 1964. 1964. Disponível em: <www.planalto.gov.br/ccivil_03/leis/14320.htm >. Acesso em: 19 abr. 2013.

BRASIL. Lei no 5.537, de 21 de novembro de 1968. 1968. Disponível em: <owww.planalto.gov.br/ ccivil_03/Leis/L5537.htm>. Acesso em: 2 maio 2013.

BRASIL. Lei no 10.260, de 12 de julho de 2001. 2001. Disponível em: <www.planalto.gov.br/ccivil_03/leis/leis_2001/110260.htm>. Acesso em: 2 maio 2013.

DIAS, Fernando A. C. Desvinculação de receitas da União, ainda necessária? Núcleo de Estudos e Pesquisas do Senado - Textos para discussão, n. 103, p. 1-25, 2011.

DIAS, Fernando A. C.; TAVARES, José F. C. Impacto da desvinculação de receitas da União no orçamento federal e em gastos sociais. Cadernos Aslegis, Brasília, v. 3, n. 9, p. 51-67, 1999.

GUIMARÃES, Ulisses. A constituição cidadã. 1988. Disponível em: <www.planalto.gov.br/ccivil_03/ revista/Rev_62/panteao/panteao.htm>. Acesso em: 8 abr. 2013.

HOLMES, Stephen; SUNSTEIN, Cass R. The cost of rights: why liberty depends on taxes. Nova York: W. W. Norton \& Company, 2000.

MALISKA, Marcos A. O direito à educação e a Constituição. Porto Alegre: S. A. Fabris, 2001.

MINISTÉRIO DO ORÇAMENTO E GESTÃO. Portaria no 42, de 14 de abril de 1999. 1999. Disponível em: < www3.tesouro.fazenda.gov.br/legislacao/download/contabili dade/portaria42.pdf>. Acesso em: 4 maio 2013.

MINISTÉRIO DO PLANEJAMENTO, ORÇAMENTO E GESTÃO. Vinculações de receitas dos orçamentos fiscal e da seguridade social e o poder discricionário de alocação dos recursos do governo federal. Brasília: Secretaria de Orçamento Federal (SOF), 2003. 
OLIVEIRA, Romualdo P. A educação na Assembleia Constituinte de 1946. In: FÁVERO, Osmar (Org.). A educação nas Constituintes brasileiras 1823-1988. 2. ed. Campinas: Autores Associados, 2001. p. 154-190.

PINTO, E. G. Seis vezes DRU: flexibilidade orçamentária ou esvaziamento de direitos sociais? De Jure — Revista Jurídica do Ministério Público de Minas Gerais, v. 11, p. 511-537, 2008.

RANIERI, Nina B. S. O direito à educação e o pleno exercício da cidadania. ComCiência, Campinas, n. 111, p. 1-3, 2009.

ROCHA, Marlos B. M. Educação conformada: a política pública de educação no Brasil, 1930-1945. Juiz de Fora: Editora UFJF, 2000.

SCAFF, Fernando F. Direitos humanos e a desvinculação de receitas da União - DRU. Revista Brasileira de Direito Constitucional, v. 4, p. 723-736, 2004.

TEIXEIRA, Maria C. O direito à educação nas Constituições brasileiras. Revista do Curso de Direito, v. 5, n. 5, p. 146-168, 2008.

TRIBUNAL DE CONTAS DA UNIÃO. Temas de destaque das contas do governo dos últimos 5 anos: 2007-2011. Brasília: TCU, Secretaria-Geral de Controle Externo, Secretaria de Macroavaliação Governamental, 2012.

Janilson Antonio da Silva Suzart é doutor em controladoria e contabilidade pela Faculdade de Economia e Administração da Universidade de São Paulo (FEA/USP), analista de finanças e controle na Secretaria do Tesouro Nacional (STN). E-mail: suzart@suzart.cnt.br. 
